\title{
Photovoltaic Energy Yield modeling under desert climates: what-if exploration of different cell technologies
}

\author{
Imre T. Horváth ${ }^{\mathrm{a}^{*}}$, Hans Goverde ${ }^{\mathrm{a}}$, Patrizio Manganiello ${ }^{\mathrm{a}}$, Jonathan Govaerts ${ }^{\mathrm{a}}$, Loic \\ Tous $^{\mathrm{a}}$, Bader Aldalalib, Eszter Vörösházia , Jozef Szlufcik ${ }^{\mathrm{a}}$, Francky Catthoor ${ }^{\mathrm{a}, \mathrm{c}}$, Jef \\ Poortmans $\mathrm{s}^{\mathrm{a}, \mathrm{c}}$ \\ ${ }^{a}$ IMEC, Kapeldreef 75, 3001 Leuven, Belgium \\ ${ }^{\mathrm{b}}$ Kuwait University, College of Engineering and Petroleum, Khaldiya, Kuwait \\ ${ }^{\mathrm{c}}$ ESAT, KU Leuven, Kasteelpark Arenberg 10, 3001 Heverlee, Belgium \\ *Corresponding author e-mail: Imre.T.Horvath@imec.be
}

\begin{abstract}
PV module testing under standard conditions is an important and well-established procedure, which plays a vital role in module rating. However, PV modules rarely operate at standard conditions therefore their field performance can only be predicted by means of models - so called energy yield models -, which combine PV module characteristics with varying environmental conditions. The present work employs a bottom-up, physics-based energy yield modelling approach, which accounts to the interacting optical, thermal and electrical mechanisms in a detailed manner. Additionally, measured data is used for the accurate calibration of the models. Such an approach permits to explore the influence of cell- and module technology details on energy yield under any specific environmental conditions. The present work employs the described method to evaluate the influence of solar cell technology on energy yield under desert climates, where high levels of insolation and elevated ambient temperature result in high PV module operating temperature, limiting energy conversion efficiency. The purpose of this work is to identify solar cell technologies and to understand the governing mechanisms, which lead to superior PV performance under the described climate conditions. The study is performed by means of physics-based exploratory energy yield simulations with detailed resolution of the thermal effects. Our comparison of four different cell technologies in monofacial modules highlights that $0.04 \% / \mathrm{C}^{\circ}$ reduction in temperature coefficient can provide $1.6 \%$ higher annual energy yield under desert climates.
\end{abstract}

Keywords: photovoltaic energy, desert climate, energy yield simulation, cell technology, temperature coefficient, thermal effect

Declarations of interest: none

\section{Introduction}

Countries of the Middle-East and North Africa (MENA) region are characterized by very high energy consumption per capita (World Bank, n.d.). Due to the climate, the main contributors for such high consumption are air conditioning and water desalination plants. An intensive further rise of electricity consumption is predicted in Kuwait, reaching $65 \%$ by 2035 , mainly caused by economic development (Osamah Alsayegh, 2015). In view of the Paris climate agreement countries of the region set ambitious goals for replacing fossil fuel sources with renewable ones. As an example for the region, the strategic target of Kuwait is to achieve a renewable energy share of $15 \%$ by 2030 (Osamah Alsayegh, 2015).

The MENA region is known to be abundant in sunshine therefore solar energy is expected to be one of the dominant contributors to the future energy mix. According to a study carried out by the Kuwait Institute for Scientific Research (KISR), during summer months $60-70 \%$ of the 
generated electric energy is consumed by air conditioning (A/C) systems (Osamah Alsayegh, 2015), whose peak consumption corresponds to highest solar irradiation on both daily and seasonal basis. This suggests that generating electricity using PV technology would naturally help to match the load and generation profiles. On the other hand the vast availability of solar resources comes with significant challenges for PV plants linked to hot and arid climates. Hence to enable cost-effective PV plant design, next to solar irradiance one should also consider the impact of elevated temperature, which causes elevated solar cell operating temperature. This in turn deteriorates photovoltaic cell performance and module reliability.

The significance of thermal effects is determined by the interplay between the thermal response of the solar cells, module materials, installation conditions and local wind conditions. Consequently, designing and optimizing photovoltaic systems for desert climates should simultaneously account for all of these parameters. Such an optimization issue can be tackled only by physics-based exploratory modeling of PV energy conversion, taking into account measured environmental conditions; cell electrical and thermal behavior, operating point; optical absorption and generation; thermal conduction, convection and radiation. This approach enables the founded extrapolation of module performance to different PV cell, module and system technologies without the necessity of calibration with outdoor data, which is - in turn - often required by parametric models.

While including all of the stated effects, the present work focuses on quantifying the performance impact of the interaction between climatic conditions and solar cell thermoelectrical behavior in order to identify cell technologies, which have the potential to maximize $\mathrm{PV}$ energy yield under desert climates. The performance impact is evaluated in terms of energy yield: the output energy divided by the peak power produced at Standard Test Conditions $\left(\mathrm{kW}_{\mathrm{p}}\right)$. The unit of energy yield is therefore $\mathrm{kWh} / \mathrm{kW}_{\mathrm{p}}$.

The employed modelling approach ensures the transparency of the findings by giving access to detailed parameters such as time series of cell temperature, current and voltage. In order to enable a more general understanding of how Energy Yield depends on cell technologies and climate conditions, simulation results for a moderate, North-West European climate are also presented and used for comparison.

The next section (Section 2) introduces the main features and the particular settings of the modelling approach, followed by the studied cell and module technologies and the input climate datasets. The results of the simulations are presented and discussed in Section 3. Finally, Section 4 summarizes the main conclusions of the work.

\section{Energy Yield modeling}

The energy yield modeling approach used in the present work employs a bottom-up, physicsbased approach. The coupled Electrical, Optical and Thermal (EOT) modelling framework requires first, measured meteorological data: ambient temperature, irradiance, wind speed and direction. Second, material properties: optical, thermal and electrical constants, thicknesses of each layer in the module. Third, cell and module technology parameters such as electrical behavior of the cell, temperature coefficients, External Quantum Efficiency, module interconnect layout serve also as input. A full description and demonstration of this modelling approach can be found in (Goverde et al., 2014), (Goverde et al., 2015), (Goverde et al., 2013) and (Anagnostos et al., 2014).

The employed approach has been developed not only for accurately modelling the energy yield of PV cells, modules and larger systems on a physics bases but also for enabling the exploration of new technologies. 


\subsection{General features of the PV energy yield modelling framework}

It is well known that the photovoltaic energy conversion process is a result of multiple, strongly coupled physical phenomena, which require an interdisciplinary modelling approach. Light interacts with the module materials through reflection, transmission and absorption. The absorbed light is then converted into electric current and voltage within the semiconductor material. The conversion generates - next to charge carriers - also heat, which deteriorates the conversion efficiency causing the importance of thermal effects in PV devices. The removal of the generated heat depends on the employed materials and the convective, conductive and radiative heat transfer processes. Due to the varying weather conditions the input parameters of such a system may vary significantly, therefore the modelling approach should respect both dynamic and static behaviors.

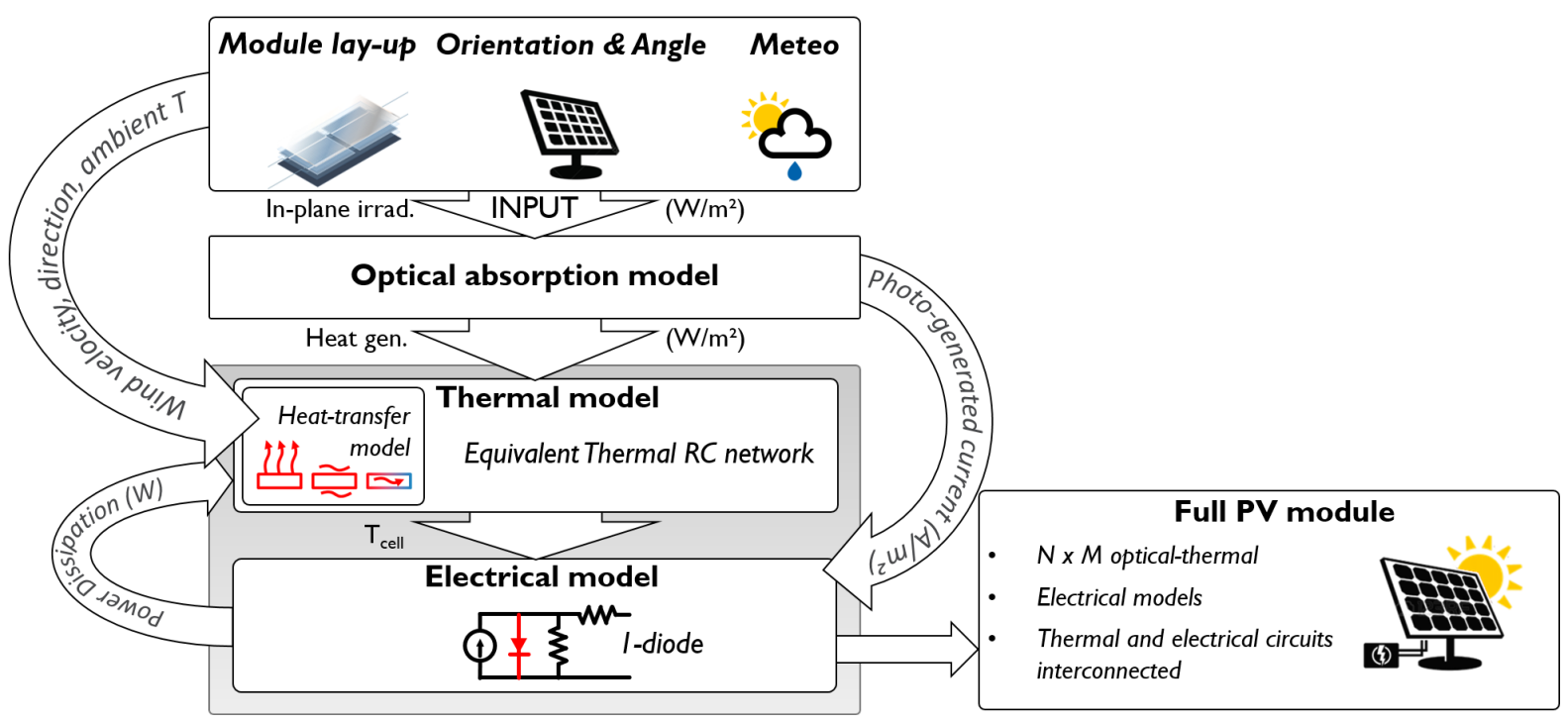

Figure 1 - Schematic representation of the Energy Yield modelling framework

The schematic representation of the developed energy yield modelling approach is shown in Figure 1. The elected approach is bottom-up, physics-based modelling. Modules are built in a hierarchical bottom-up approach, starting with single PV cells, which can then be interconnected to form modules or arrays of modules. The model input parameters are defined by measured high temporal resolution weather data including irradiation, ambient temperature, wind speed and direction. Using an optical pre-processing step, the in-plane irradiance on the PV module is calculated. The incident irradiation is converted into light-generated current, which then forms the input of the electrical circuit model. The latter uses the single diode equation with a temperature dependent diode, series and shunt resistances, providing high accuracy at acceptable computational costs. The thermal model considers each layer of the complete PV module. The thermal model is represented by an equivalent resistor-capacitor (RC) circuit with physical dimensions and material properties represented by equivalent thermal resistances and capacitors. The circuit is placed in a two-way coupling with the electrical circuit: the electrical circuit feeds dissipated power to the thermal circuit, which in turn computes and feeds back the junction temperature to the electrical model. Thermal radiation and convective cooling of the module surfaces is modelled by means of inputdependent thermal resistors, which may have time-varying, highly non-linear properties. Model outputs are available with high temporal resolution for all nodes and branches of the two networks, therefore all voltages, currents and temperatures can be obtained for each cell and material layer. A behavioral maximum power point tracking (MPPT) algorithm completes the model, which allows to analyze the direct current (DC) output power in realistic conditions 
including temporal fluctuations and mismatches due to partial shading (Anagnostos et al., 2014).

For the sake of the present study energy yield simulations are performed using a single cell model, where interconnection losses are not accounted for. It is noted however that series losses caused by interconnection may influence the thermal behavior of a PV module (Haschke et al., 2017). System level losses such as wiring and inverter losses are also not simulated, since these losses are not expected to interfere with the differences resulting from varied cell technologies. The simulations are performed using climate data measured at 1 minute resolution. Since thermal transients upon sudden changes of irradiation and wind cooling are expected to be important, the simulations are performed with a beyond state-of-the-art 1 second resolution. The 1 second resolution weather data is obtained by linearly interpolating the 1 minute resolution data. The extracted quantities are the instantaneous DC output power at the Maximum Power Point (MPP) and the instantaneous cell temperature. The detailed setup of the model used in this study is given in the following sections.

\subsection{Simulated cell technologies}

As later described in Section 2.3.2 the solar cell is modeled on a behavioral basis by representing its electrical characteristics using a precisely calibrated temperature dependent single diode model. Different cell technologies are therefore implemented by means of setting the appropriate diode parameters to values extracted from solar cell characterization measurements: short circuit current, open circuit voltage, maximum power point current and voltage, temperature coefficient of open circuit voltage, which are provided only at standard conditions. Three of the studied four solar cells have been manufactured in-house using different technologies: hybrid SHJ, p-PERC and n-PERT. The fourth cell type uses the Al-BSF technology and it is included as a reference, since it is the most frequently used cell technology at the moment. The technological details, manufacturing processes and the careful characterization of these cells have been reported in (Haschke et al., 2017). Their detailed 
discussion is beyond the scope of this paper, nevertheless, Figure 2 illustrates the main features of these technologies.

\subsection{Energy yield modelling under desert climates}

The main characteristics of desert climates from the aspect of PV energy conversion are high

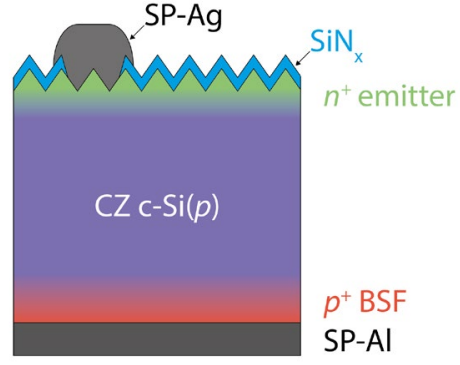

AI BSF

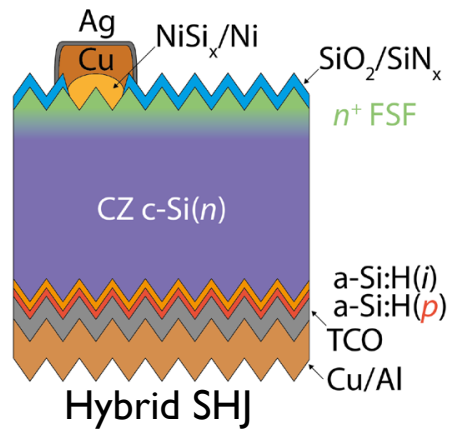

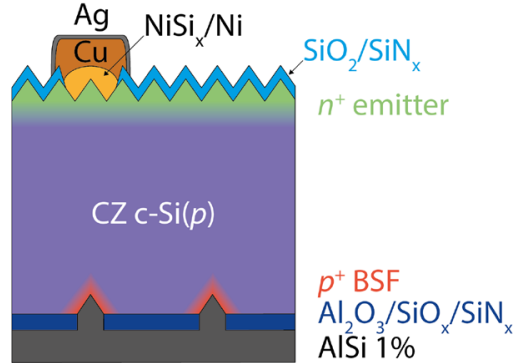

P-PERC

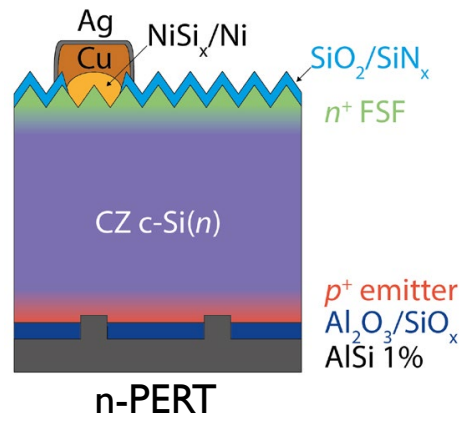

levels of irradiance with low variability and high ambient temperatures as illustrated later by Figure 5 and Figure 6 . These two conditions cause high operating temperatures in the PV cells, which in turn reduce their efficiency. Additional challenges not treated in this work include enhanced PV module degradation due to high operating temperatures and losses due to soiling in a dusty environment.

Consequently, it is important to realistically model the thermal behavior of cells and modules if PV energy yield is to be calculated under desert climates.

\subsubsection{Temperature dependent diode}

As mentioned before, the core of the electrical model is the temperature dependent diode, which is described by the classical single diode equation:

$$
I=I_{l}-I_{0}\left[e^{\left(\frac{q\left(V+I N_{S} R_{S}\right)}{N_{s} n k T}\right)}-1\right]-\frac{V+I N_{S} R_{S}}{N_{S} R_{p}}
$$

where $I$ and $V$ are the diode current and voltage, $I_{l}$ is the photo-generated current, $I_{0}$ is the reverse saturation current, $q$ is the electron charge, $N_{s}$ is the number of series-connected cells, $n$ is the diode ideality factor, $k$ is the Boltzmann constant, $T$ is cell temperature, $R_{s}$ and $R_{p}$ are the series and shunt resistances, respectively. This model has 5 parameters, which are $I_{l}, I_{0}, n$, $R_{s}$ and $R_{p}$. Equation 1 is capable of accurately representing the I-V characteristics of a solar cell provided that all 5 parameters are set properly. The latter is a non-trivial task because of two main reasons. First, Equation 1 is implicit in $I$, which renders its mathematical treatment more difficult; second, there are many combinations of the 5 parameters, which approximately reproduce the I-V characteristics of a given solar cell. The thermal behavior of the diode is also encoded in Equation 1: $I_{l}$ is known to depend on temperature; $I_{0}$ depends on temperature also 
as described by Equation 2; $T$ directly appears in the denominator of the exponent of Equation 1 .

$$
I_{0}=I_{0, r e f}\left[\frac{T}{T_{r e f}}\right]^{3} e^{\left(\frac{E_{g, r e f} \cdot E_{g}}{k T_{r e f} \cdot k T}\right)}
$$

In Equation 2 the subscript ref denotes reference conditions e.g. Standard Test Conditions (STC), $E_{g}$ is the bandgap energy of the semiconductor material at temperature T and $E_{g, r e f}$ is the bandgap energy at temperature $T_{\text {ref }}$.

It is now apparent that calibrating this five-parameter model only on the basis of a satisfactory fit to the measured I-V curve will impose a certain almost arbitrary thermal behavior. Therefore it is essential to constrain the diode thermal behavior during the fitting procedure either by incorporating additional equations or by fitting multiple I-V curves measured under different cell temperatures.

\subsubsection{Diode model calibration procedure}

Calibrating the five-parameter diode model consists of fitting the model to I-V curve points provided by measurements or cell/module datasheets. Using measured points - when available - enables superior accuracy, however, using datasheet values is advantageous when cell/module types need to be explored, for which, measurement data is not available. No matter, which procedure is followed, the same fitting algorithm can be used with different equations. The present work uses the model published in (De Soto et al., 2006) together with the parameter extraction method described in (Laudani et al., 2013). The algorithm is improved to be fully automatic, without needing any initial guesses and to work with both measured I-V curves and module datasheet values. Currently only the temperature dependency of the open circuit voltage is considered. The algorithm results in a good fit to the device datasheet values and closely respects the prescribed temperature coefficients. The IV curve fit corresponding to the n-PERT cell is shown in Figure 3.

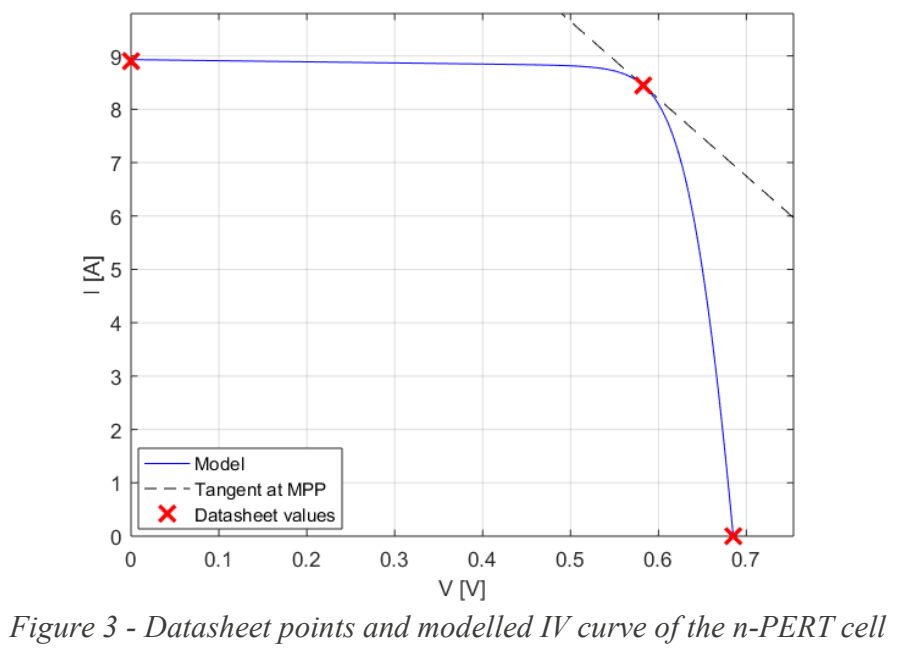

The quality of the model calibration can be analyzed in terms of how well the characteristic datasheet values are approximated. Table 1 displays the percentage difference between

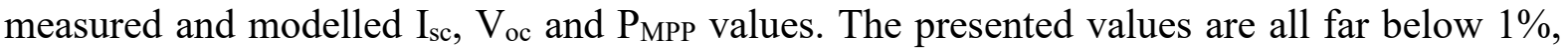
suggesting that the model calibration is performed with sufficiently high accuracy.

\begin{tabular}{lccc} 
& $\Delta \mathrm{I}_{\mathrm{sc}}[\%]$ & $\Delta \mathrm{V}_{\mathrm{oc}}[\%]$ & $\Delta \mathrm{P}_{\mathrm{MPP}}[\%]$ \\
\hline Al-BSF & 0.076 & 0.0078 & 0.082 \\
p-PERC & 0.056 & 0.00031 & 0.011 \\
Hybrid SHJ & 0.13 & 0.015 & 0.084
\end{tabular}


Table 1 - Summary of the relative percentage error between nominal and modelled characteristic values for the four examined cell technologies

The characteristic main feature of the studied cell technologies is the temperature coefficient. It is expected that the temperature coefficient strongly influences the energy yield of PV modules under hot climates. Table 2 summarizes the nominal and modelled temperature coefficient values together with the relative percentage errors for the four solar cell types. The TC values of the cell models are evaluated using LT Spice circuit simulations.

\begin{tabular}{lccc} 
& nominal TC $\left[\mathrm{mV} /{ }^{\circ} \mathrm{C}\right]$ & model TC $\left[\mathrm{mV} /{ }^{\circ} \mathrm{C}\right]$ & relative error $[\%]$ \\
\hline Al-BSF & -1.9435 & -2.024 & 4.14 \\
Hybrid SHJ & -1.887 & -1.968 & 4.29 \\
p-PERC & -1.8501 & -1.931 & 4.37 \\
n-PERT & -1.8135 & -1.897 & 4.6
\end{tabular}

Table 2 - Summary of nominal and modelled temperature coefficient values (for open circuit voltage) and their relative differences. Different cell technologies are listed from top to bottom in a descending order of temperature coefficient.

The error of the modelled temperature coefficient value is under 5\% in all cases. Modelled temperature coefficient values forecast - in general - slightly stronger operating temperature dependency compared to the real solar cells. However, since the magnitude and the tendency of the difference is similar for all solar cells, the comparison is expected to be unaffected.

In fact, the energy conversion trend resulting from differences in thermal behavior is not directly affected by the absolute temperature coefficient because $V_{O C}$ may significantly vary between different technologies. Instead, the relative temperature coefficient $\left(\mathrm{TC}_{\mathrm{rel}}=\right.$ $\left.\mathrm{TC} / \mathrm{V}_{\mathrm{OC}}{ }^{*} 100\right)\left[\% /{ }^{\circ} \mathrm{C}\right]$ gives a better indication. The latter value is presented for the four cell technologies in Table 3. One may observe that the Hybrid SHJ and p-PERC cells change their places in the classification with respect to Table 2 due to the higher $\mathrm{V}_{\text {OC }}$ of the hybrid SHJ cell.

\begin{tabular}{lcc} 
& Cell $\mathrm{V}_{\mathrm{OC}}[\mathrm{mV}]$ & model $\mathrm{TC}_{\text {rel }}\left[\% /{ }^{\circ} \mathrm{C}\right]$ \\
\hline Al-BSF & 638.6 & -0.32 \\
p-PERC & 653.5 & -0.3 \\
Hybrid SHJ & 677 & -0.29 \\
n-PERT & 685.1 & -0.28
\end{tabular}

Table 3 - Cell VOC and modelled relative temperature coefficient values of the studied cell technologies. Cell technologies are ordered from top to bottom according to descending relative temperature coefficients

\subsubsection{Simulated module layup}

The purpose of the present work is to explore the energy yield impact of using different PV cell technologies under a desert climate. Accordingly, the module materials are not varied between the examined configurations. However, the material properties play an important role in the heat management of the PV module therefore their accurate modeling is essential.

The thermal behavior of the PV module is modelled as a thermal equivalent RC circuit. Each layer is characterized by a thermal resistance and capacitance, which are in parallel connection. The model follows the 'Continued fraction circuit' scheme. The module layers are from back to front: back sheet (Polyvinyl fluoride), encapsulant (EVA), Si wafer, encapsulant (EVA), glass. Thermal resistances and capacitances are calculated from the physical properties of the different materials with layer thicknesses and areas also considered. 


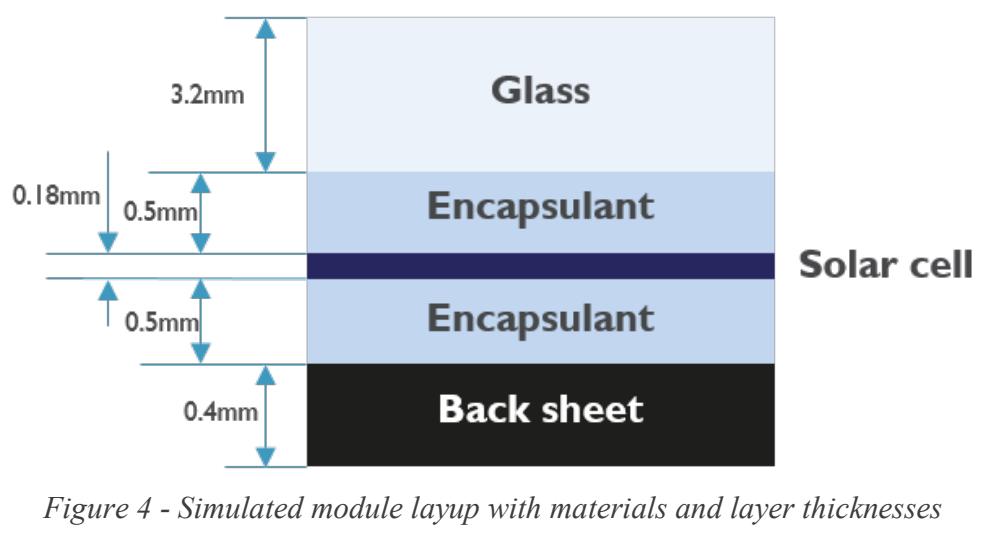

\subsubsection{Module configuration}

The simulated modules face south and they are tilted at $30^{\circ}$ from horizontal, which is optimal for the highest annual in-plane insolation under the latitude of Kuwait city $29,33^{\circ}$. The ground surface albedo is assumed to be 0.2. The direct and ground-reflected in-plane irradiance components are computed from the measured irradiance values using standard trigonometric expressions, while the diffuse component on the tilted plane is computed by means of the Perez model (Perez et al., 1987).

\subsection{Climate data}

The Kuwait climate data was provided by the Kuwait Institute for Scientific Research (KISR) at their Shagaya renewable energy park location. The climate data used in this study is acquired with high temporal resolution ( 1 minute) during the year 2014 from the $1^{\text {st }}$ January until the $31^{\text {st }}$ December. The dataset contains measurements of irradiance components: global horizontal irradiance (GHI), diffuse horizontal irradiance (DHI) and direct normal irradiance (DNI); wind speed and wind direction; ambient temperature and pressure; relative humidity; time.

\subsubsection{Climate data overview}

According to the Köppen-Geiger climate classification Kuwait belongs to the category 'BWh', which signifies arid (B), desert (W), hot arid (h) and as such it is therefore well suited to study PV Energy Yield at desert climates. The following figures provide an overview of the main characteristics of such a climate, as opposed to a North-West European climate dataset recorded in Oldenburg, Germany. The Köppen-Geiger class of the latter is Cfb i.e. warm temperature (C), fully humid (f), warm summer (b).

First, it is worthwhile to analyze the yearly distribution of GHI by means of contour plots, where the coordinates are date and time and colors relate to the value of GHI in dimensions of $\mathrm{W} / \mathrm{m}^{2}$. 

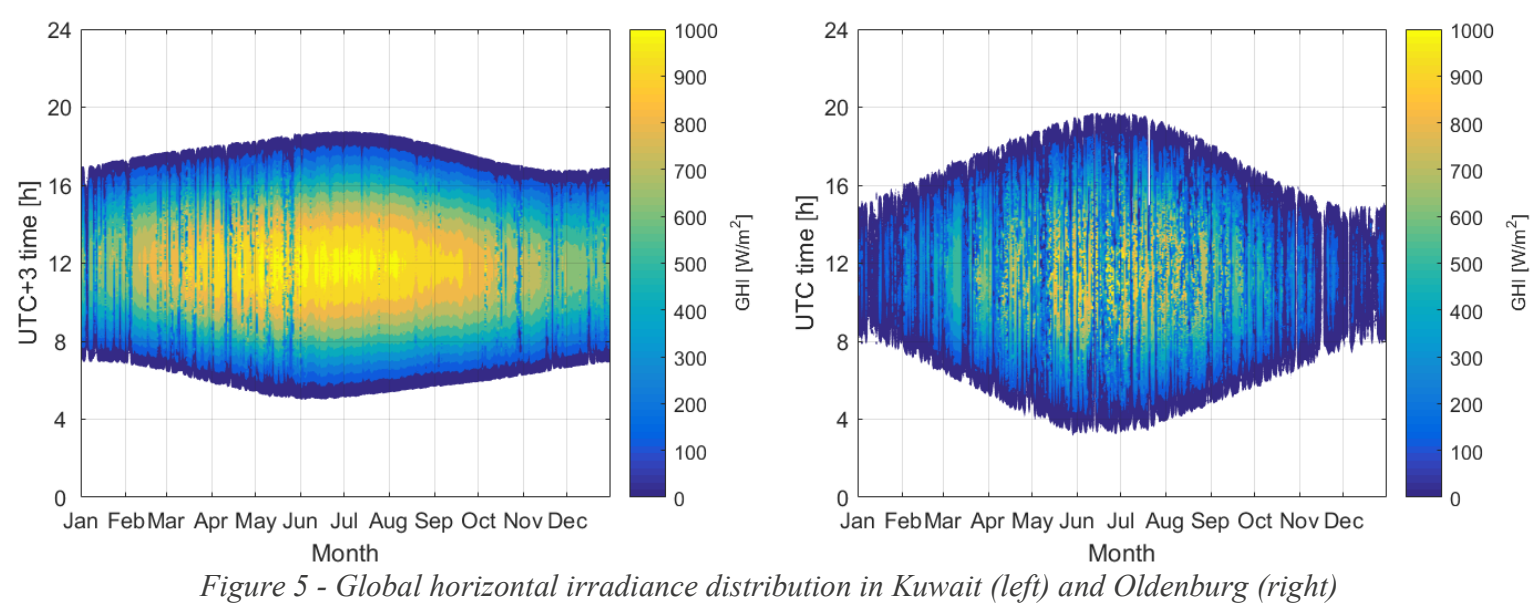

Figure 5 highlights the main differences between the two climates in terms of solar irradiation. Kuwait has high levels of solar irradiation with low day-to-day variability throughout the entire year. Due to the geographic location, the number of daylight hours shows low yearly variation. Summer months are characterized by almost uninterrupted clear sky days and most of the cloudy days occurred during spring in 2014. The Oldenburg climate is significantly different in terms of solar irradiation. Variable sky conditions are dominant throughout the year, although peak irradiance levels are comparable to those in Kuwait. Due to the high latitude of Oldenburg the variability of daylight hours is significant: winter days have less than 8 hours of daylight, while during summer up to 16 hours of daylight is observed. The total yearly GHI differs by a factor of two in favor of Kuwait: annual GHI in Kuwait in 2014 was $2170 \mathrm{kWh} / \mathrm{m}^{2}$ compared to $1050 \mathrm{kWh} / \mathrm{m}^{2}$ in Oldenburg.

Another important meteorological parameter affecting PV energy conversion is ambient temperature. The daily maximum ambient temperature of the above two climates during 2014 is compared in Figure 6. In accordance with the expectations higher maximum temperatures occur in Kuwait. The differences are in the order of 10 degrees during winter but up to 20 degrees higher temperatures were measured in Kuwait during summer months.

High levels of irradiance and ambient temperature cause elevated PV module operating temperatures, however the complete picture is only obtained when the wind cooling effect is taken into account.

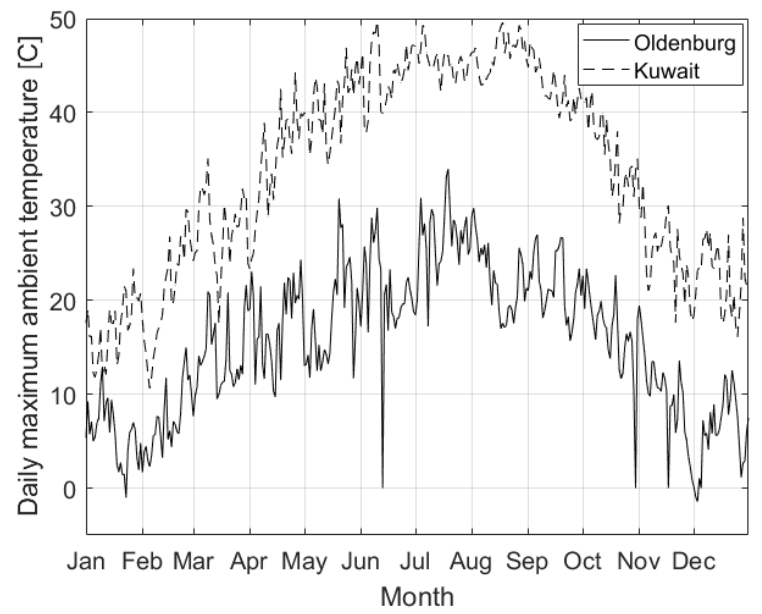

Figure 6 - Maximum daily ambient temperature during 2014 in Kuwait and Oldenburg

Wind cooling is modelled in the present framework using variable thermal resistors, where thermal resistance is set as a calibrated function of local freestream wind speed. Since the wind measurements were obtained at a high altitude, the Kuwait wind speed measurements were 
vertically extrapolated to the approximate height of the PV installation, which is assumed to be $3 \mathrm{~m}$ above ground. The assumed atmospheric boundary layer profile is described by the classical 1/7 power law, which is well suited to characterize atmospheric boundary layers in well-exposed desert regions with low surface roughness (Al-Nassar et al., 2005). No such correction is needed on the wind speed measurements from the Oldenburg site since the anemometer setup was located right beside the irradiance and temperature sensors. Wind speed histograms measured in Kuwait and Oldenburg are compared in Figure 7. The range of occurring wind speeds are similar for the two sites: speeds higher than $12 \mathrm{~m} / \mathrm{s}$ are hardly ever measured. However, the distribution of wind speeds is different: the median wind speed in Kuwait is between $4-5 \mathrm{~m} / \mathrm{s}$ while it is only the half of it $(2 \mathrm{~m} / \mathrm{s})$ in Oldenburg. Such a significant difference is accounted to the fact that the Oldenburg site is located in an urban environment where lower wind speed is expected relative to a desert site. It is also possible that measuring wind speeds near ground level at the Kuwait site would give slightly different results.
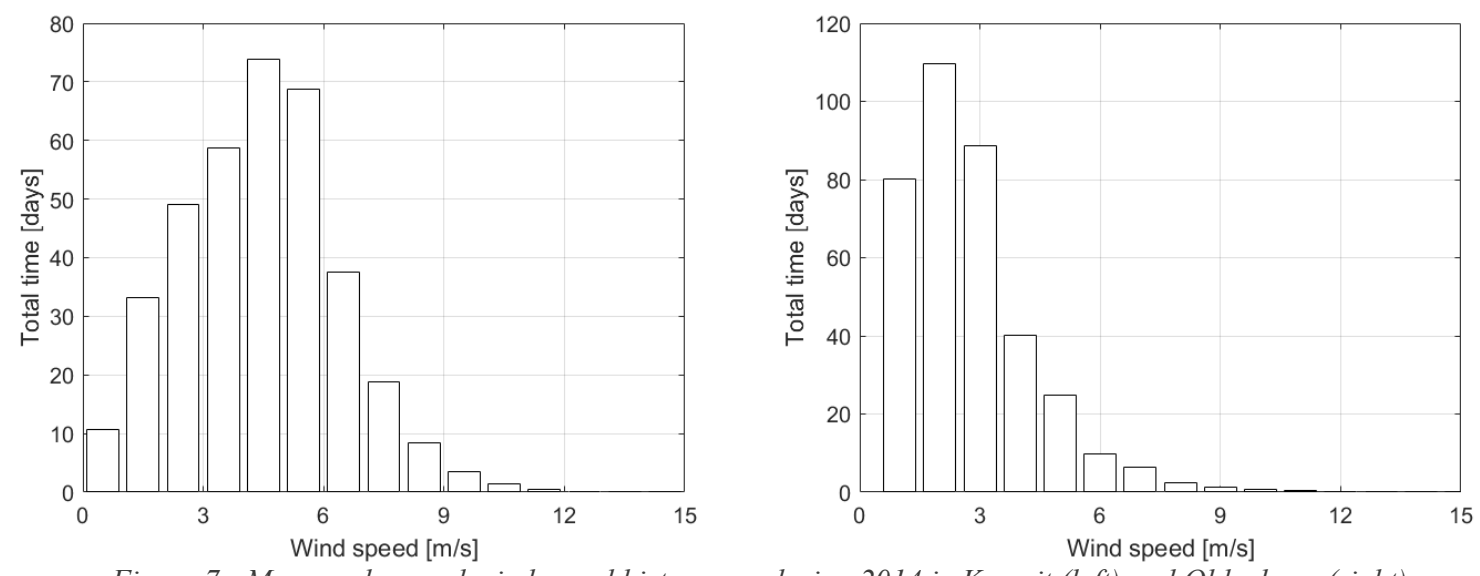

Figure 7 - Measured annual wind speed histograms during 2014 in Kuwait (left) and Oldenburg (right)

Due to the mechanism of convective cooling it is expected that the cooling effect is stronger when the wind speed over the PV module surface is larger. Since both sites are on the northern hemisphere, the highest PV performance is expected from south-facing modules. In view of this, the annual wind direction distributions are worthwhile to analyze. These are presented by Figure 8.
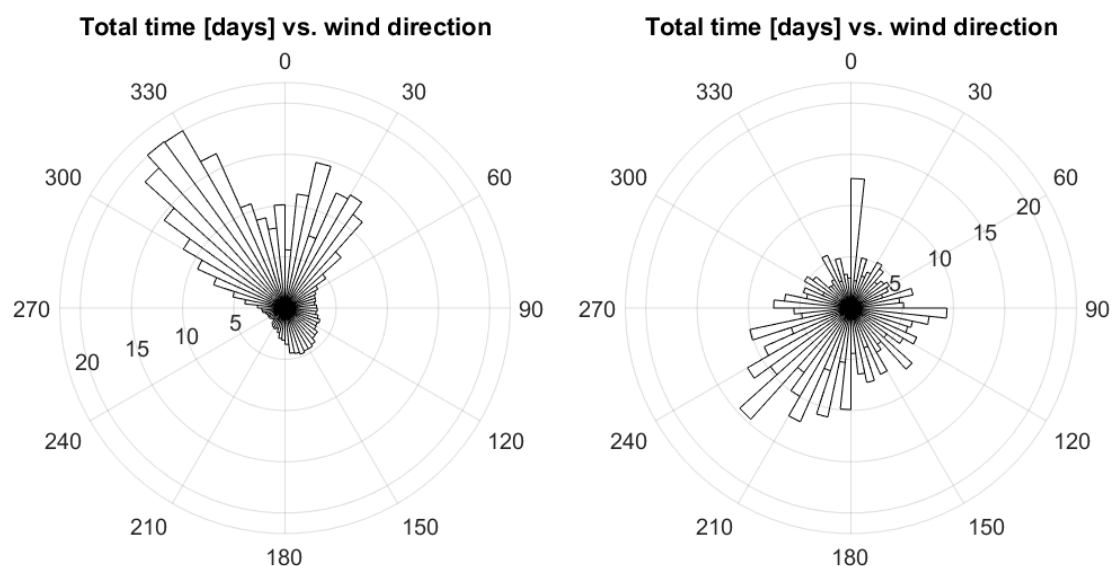

Figure 8 - Wind direction distributions at the Kuwait (left) and Oldenburg (right) measurement sites

It can be concluded that governing wind directions are different between the two sites. The Kuwait site receives most of the wind from a north-westerly, northerly direction. The variability of wind direction at the Oldenburg site is more pronounced due to the urban characteristics of its environment: high buildings modify the atmospheric boundary layer 
through increasing surface roughness, lowering average wind speed and enhancing variability. The governing wind direction on the latter site is south-westerly.

\section{Results}

The results of the annual energy yield calculations for the different cell technologies under the Kuwait climate are presented by Figure 9. Highest energy yield is reached with the n-PERT cell, followed by the hybrid SHJ and p-PERC technologies. The standard Al BSF cell obtains the lowest energy yield. It is worth noticing that the ranking based on energy yield is identical to the one based on relative temperature coefficients (Table 3) i.e. the lowest thermal sensitivity results in the highest energy yield.

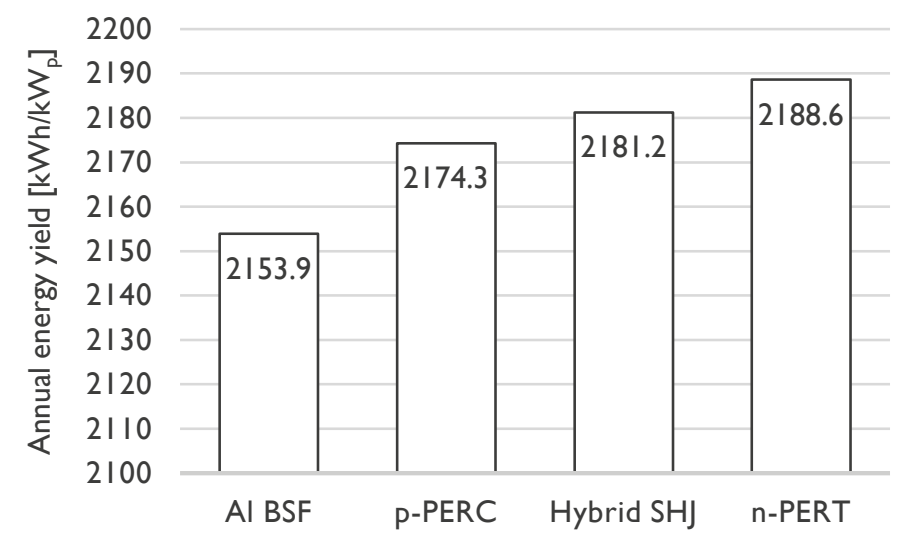

Figure 9 - Modeled annual energy yield values for different cell technologies

The obtained energy yield difference is merely the result of different cell thermal behaviors: module thermal properties, optical properties are identical for the four different cases and differences in electrical behavior are excluded by analyzing energy yield instead of output energy. The energy yield difference between the best (n-PERT) and worst (Al BSF) cell is $1.6 \%$. The same difference was found to be $1.2 \%$ under the Oldenburg climate $(\mathrm{H}$. Goverde et al., 2017). The reduced influence of the temperature coefficient stems from the lower cell operating temperature at the Oldenburg climate. This confirms that low solar cell thermal coefficient helps to enhance energy yield at hot and sunny climates. In order to quantify the difference between the two climates in terms of cell operating temperature, these values are extracted from the energy yield models. The module temperature data including nighttime is displayed in Figure 10 as annual histogram distributions. 


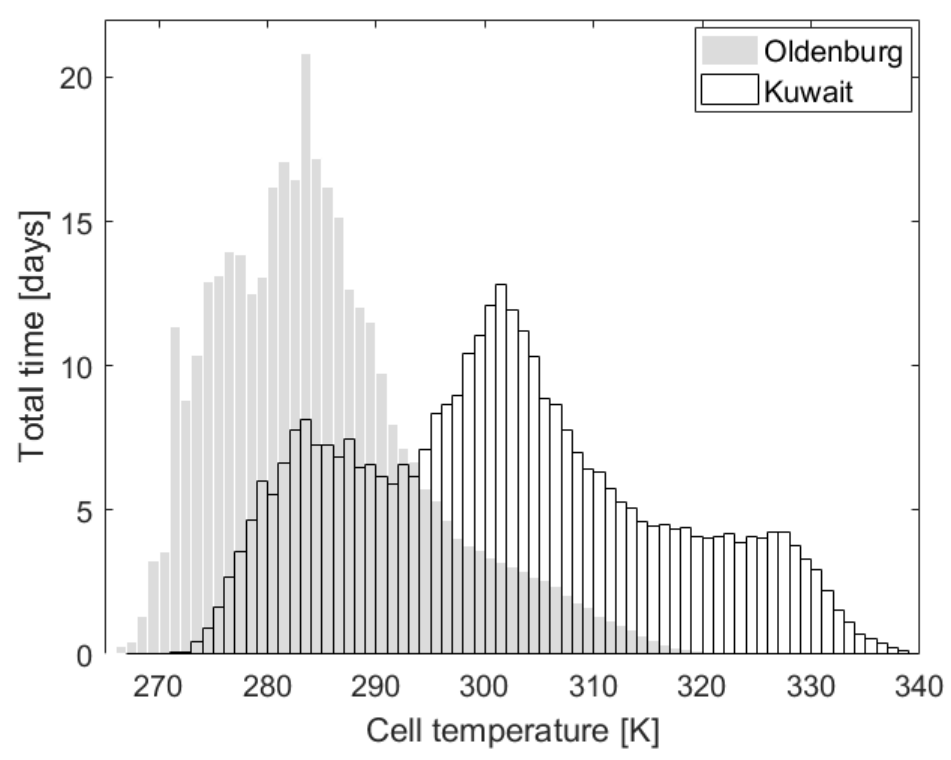

Figure 10 - Modelled annual module temperature histograms calculated with the n-PERT cell technology. The plotted data includes night-time module temperatures as well.

Figure 10 shows that average cell temperature in Kuwait is significantly higher: annual mean module temperature in Oldenburg is $12{ }^{\circ} \mathrm{C}$ while it is $28.7^{\circ} \mathrm{C}$ in Kuwait. The difference between lowest and highest values in Oldenburg is $55^{\circ} \mathrm{C}$ and it is $70{ }^{\circ} \mathrm{C}$ in Kuwait. The temperature distributions have distinct shapes, resulting from a superposition of nighttime ambient temperature and daytime module temperature, which form relevant inputs for module reliability analysis.

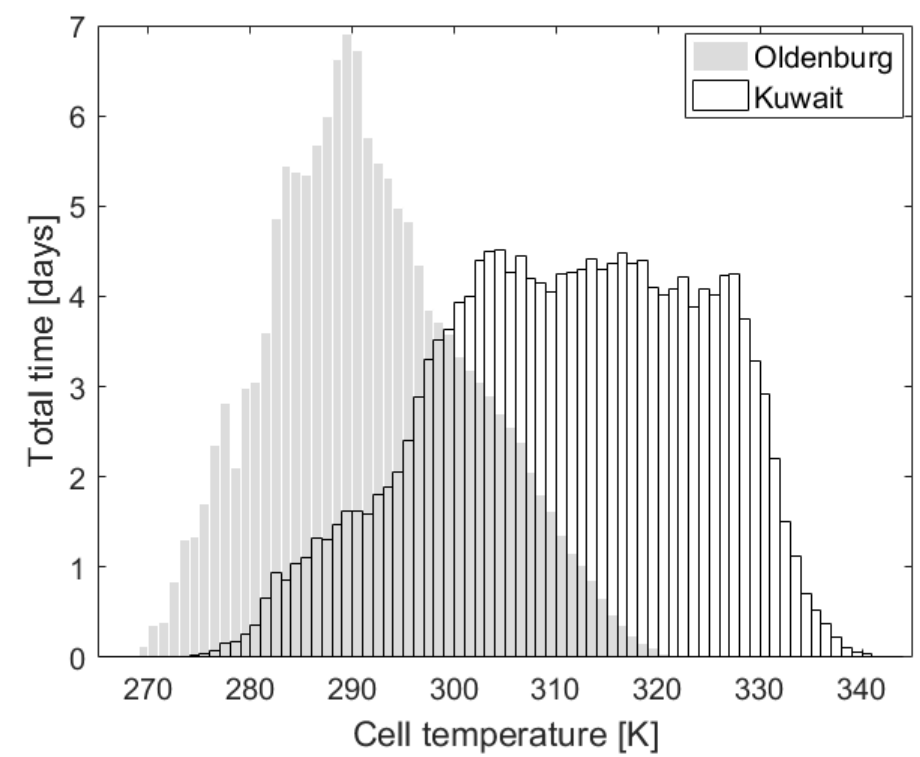

Figure 11 - Modelled annual module temperature histograms during daytime calculated with the n-PERT cell technology

In order to better understand the cell temperature dependency of energy conversion, temperatures are extracted only in moments when the power output is equal to or larger than $1 \%$ of the STC power output. The resulting histogram distributions are shown in Figure 11. The daily mean temperature during energy production in Oldenburg is $18.9^{\circ} \mathrm{C}$ and $38.1{ }^{\circ} \mathrm{C}$ in Kuwait. Excluding hours when energy is not being produced reduces the range of occurring module temperatures by $5^{\circ} \mathrm{C}$ at both climates. The latter operation significantly alters the 
temperature distribution shape only at the Kuwait climate, which highlights again that alternating very high daytime module temperature and moderate nigh-time ambient temperature imposes significant strain on the PV modules.

One parameter commonly used for evaluating the optimality of PV system operation is the Performance Ratio (PR). It is expected that this value decreases when the solar cells operate at high temperatures, since PR is defined as the quotient of the actual produced energy to the theoretical maximum output energy. The latter is calculated from the actual insolation value and the STC efficiency of the module. PR takes values between 0 and 1 . The daily PR difference between the best (n-PERT) and worst (Al BSF) energy yield cell is shown by Figure 12 for the entire year. One may observe that the n-PERT cell always displays somewhat superior PR, however, the advantage becomes most significant as ambient temperature and insolation increases towards summer. The highest observed persistent difference reaches 0.02 in favor of the n-PERT cell, corresponding to $2 \%$ absolute gain in exploiting the potential of the given cell. Another interesting phenomenon observed in Figure 12 is that on very cloudy days the n-PERT cell has a more significant PR advantage, reaching 0.05 on some specific days. This is due to the better low light performance of the n-PERT cell relative to the Al-BSF cell (Krügener and Harder, 2013).

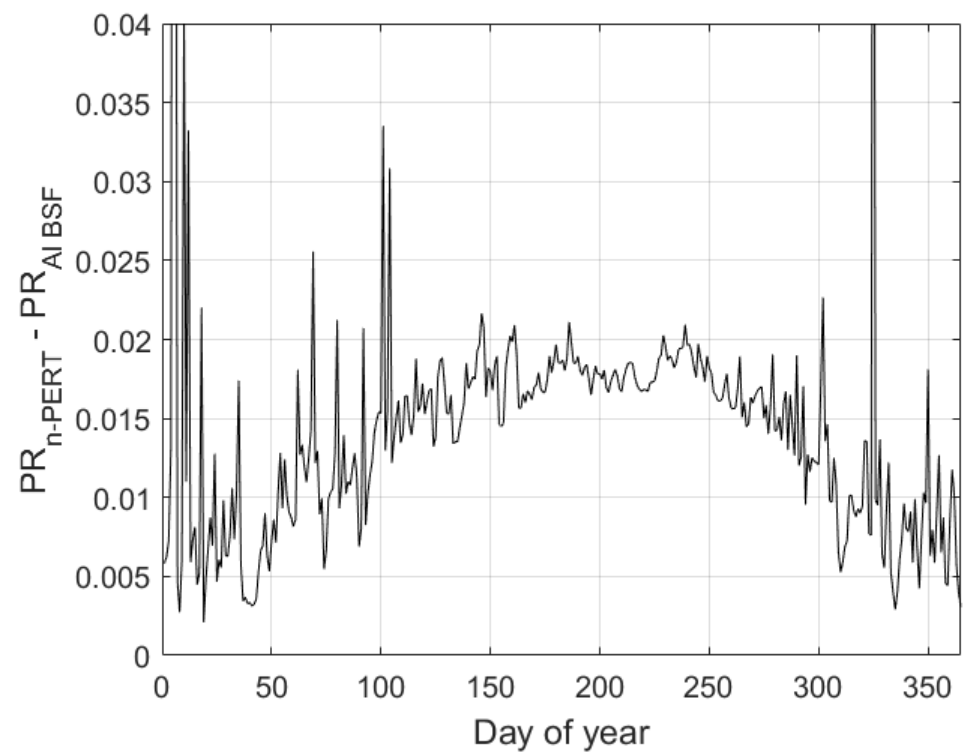

Figure 12 - Difference of Performance Ratio between the best (n-PERT) and worst (Al BSF) energy yield cell

\section{Conclusions}

It is shown that physics-based energy yield modelling is the appropriate approach for studying the energy yield of PV systems built on various cell and module technologies. The presented study focuses on exploring the energy yield impact of using different cell technologies under a desert climate. Particular attention is payed to input climate data and to accurately modelling the complex PV module operation: cell electrical behavior and its coupling to the cell - module thermal response. The resulting simulation framework is capable of resolving energy yield differences caused by differences of technological details. In particular, it is shown that an absolute difference of $0.04 \% /{ }^{\circ} \mathrm{C}$ in relative open-circuit temperature coefficient has an important impact on annual energy yield, amounting to $1.6 \%$ under a desert climate and $1.2 \%$ under a moderate climate. Analyzing the yearly module temperature distributions helps to pinpoint the source of this difference, which is the very high operating temperature under the desert climate. The latter has a yearly average value of $38.1^{\circ} \mathrm{C}$. The influence of the high operating temperature can be further identified by analyzing the progression of the daily performance ratio difference between the best and worst performing cell. This shows a clear 
seasonal variation: starting with low values in winter and reaching high values up to 0.02 i.e. $2 \%$ in absolute performance ratio during summer. It is also observed that on very cloudy days the low light behavior of the cells dominates the performance ratio differences.

In conclusion, from the investigated cell types the n-PERT technology promises the highest annual energy yield, which is $1.6 \%$ higher than the standard Al BSF cells, making the n-PERT cell the most suited (among the four studied technologies) cell type to be installed under desert climates.

The current work demonstrates the potential of the described physics-based energy yield modelling approach for exploring new technologies, however, efforts were focused on understanding solely the influence of solar cell characteristics. The exploration and cooptimization of different module materials, interconnection technologies and plant designs for maximum energy yield may provide further economic and scientific gains therefore they will form the subject of future studies.

\section{Acknowledgements}

The climate data from Kuwait was provided by the Kuwait Institute for Scientific Research (KISR).

Funding: European Union, the European Regional Development Fund ERDF, Flanders Innovation \& Entrepreneurship and Province of Limburg. Funding agencies and the industrial partners of the imec Industrial Affiliation Program in SiPV, and the EFRO-SALK SolSThore project, Kuwait Foundation for the Advancement of Sciences under project number [P11515EE-01].

Furthermore, the authors gratefully acknowledge T. Borgers and A. van der Heide for their support and advice.

\section{References}

Al-Nassar, W., Alhajraf, S., Al-Enizi, A., Al-Awadhi, L., 2005. Potential wind power generation in the State of Kuwait. Renewable Energy 30, 2149-2161. https://doi.org/10.1016/j.renene.2005.01.002

Anagnostos, D., Goverde, H., Catthoor, F., Soudris, D., 2014. Presentation of a Verilog-AMS model for detailed transient electro-thermal simulations of PV modules and systems. Presented at the 29th EU PVSEC.

De Soto, W., Klein, S.A., Beckman, W.A., 2006. Improvement and validation of a model for photovoltaic array performance. Solar Energy 80, 78-88. https://doi.org/10.1016/j.solener.2005.06.010

Goverde, H., Anagnostos, D., Herteleer, B., Govaerts, J., Baert, K., Aldalali, B., Catthoor, F., Driesen, J., Poortmans, J., 2015. Model requirements for accurate short term energy yield predictions during fast-varying weather conditions. Presented at the 31 st EU PVSEC.

Goverde, H., Govaerts, J., Baert, K., Catthoor, F., Driesen, J., Poortmans, J., 2013. OpticalThermal-Electrical Model for a Single Cell PV Module in Non-Steady-State and NonUniform Conditions Built in Spice. Presented at the 28th EU PVSEC.

Goverde, H., Herteleer, B., Anagnostos, D., Köse, G., Goossens, D., Aldalali, B., Govaerts, J., Baert, K., Catthoor, F., Driesen, J., Poortmans, J., 2014. Energy Yield Prediction Model for PV Modules Including Spatial and Temporal Effects. Presented at the 29th EU PVSEC. 
H. Goverde, D. G. Anagnostos, J. Govaerts, P. Manganiello, E. Voroshazi, K. Baert, J. Szlufcik, F. Catthoor, J. Poortmans, J. Driesen, 2017. Accurately Simulating PV Energy Production: Exploring the Impact of Module Build-Up. Presented at the EU PVSEC 2017.

Haschke, J., Seif, J.P., Riesen, Y., Tomasi, A., Cattin, J., Tous, L., Choulat, P., Aleman, M., Cornagliotti, E., Uruena, A., others, 2017. The impact of silicon solar cell architecture and cell interconnection on energy yield in hot \& sunny climates. Energy \& Environmental Science 10, 1196-1206.

Krügener, J., Harder, N.-P., 2013. Weak Light Performance of PERC, PERT and Standard Industrial Solar Cells. Energy Procedia 38, 108-113. https://doi.org/10.1016/j.egypro.2013.07.256

Laudani, A., Mancilla-David, F., Riganti-Fulginei, F., Salvini, A., 2013. Reduced-form of the photovoltaic five-parameter model for efficient computation of parameters. Solar Energy 97, 122-127. https://doi.org/10.1016/j.solener.2013.07.031

Osamah Alsayegh, 2015. Kuwait needs to rethink its energy mix. Oxford Energy Forum November 2015.

Perez, R., Seals, R., Ineichen, P., Stewart, R., Menicucci, D., 1987. A new simplified version of the Perez diffuse irradiance model for tilted surfaces. Solar energy 39, 221-231.

World Bank, n.d. World development indicators: Energy production and use [WWW Document]. World Bank website. URL http://wdi.worldbank.org/table/3.6 (accessed 11.8.17). 